Article

\title{
Diversity and Bioactive Potential of Actinobacteria from Unexplored Regions of Western Ghats, India
}

\author{
Saket Siddharth ${ }^{1}$, Ravishankar Rai Vittal ${ }^{1, *}$, Joachim Wink ${ }^{2}$ and Michael Steinert ${ }^{3}$ \\ 1 Department of Studies in Microbiology, University of Mysore, Manasagangotri, Mysore 570 006, India; \\ saketsiddharth@gmail.com \\ 2 Microbial Strain Collection, Helmholtz Centre for Infection Research GmbH (HZI), Inhoffenstrasse 7, \\ 38124 Braunschweig, Germany; joachim.wink@helmholtz-hzi.de \\ 3 Institute of Microbiology, Technische Universität Braunschweig, 38106 Braunschweig, Germany; \\ m.steinert@tu-bs.de \\ * Correspondence: raivittal@gmail.com
}

Received: 3 February 2020; Accepted: 6 February 2020; Published: 7 February 2020

\begin{abstract}
The search for novel bioactive metabolites continues to be of much importance around the world for pharmaceutical, agricultural, and industrial applications. Actinobacteria constitute one of the extremely interesting groups of microorganisms widely used as important biological contributors for a wide range of novel secondary metabolites. This study focused on the assessment of antimicrobial and antioxidant activity of crude extracts of actinobacterial strains. Western Ghats of India represents unique regions of biologically diverse areas called "hot spots". A total of 32 isolates were obtained from soil samples of different forest locations of Bisle Ghat and Virjapet situated in Western Ghats of Karnataka, India. The isolates were identified as species of Streptomyces, Nocardiopsis, and Nocardioides by cultural, morphological, and molecular studies. Based on preliminary screening, seven isolates were chosen for metabolites extraction and to determine antimicrobial activity qualitatively (disc diffusion method) and quantitatively (micro dilution method) and scavenging activity against DPPH (2,2-diphenyl-1-picrylhydrazyl) and ABTS (2,2'-Azino-bis(3-ethylbenzothiazoline-6-sulfonic acid) radicals. Crude extracts of all seven isolates exhibited fairly strong antibacterial activity towards MRSA strains (MRSA ATCC 33591, MRSA ATCC NR-46071, and MRSA ATCC 46171) with MIC varying from 15.62 to $125 \mu \mathrm{g} / \mathrm{mL}$, whereas showed less inhibition potential towards Gram-negative bacteria Salmonella typhi (ATCC 25241) and Escherichia coli (ATCC 11775) with MIC of 125-500 $\mu \mathrm{g} / \mathrm{mL}$. The isolates namely S1A, SS5, SCA35, and SCA 11 inhibited Fusarium moniliforme (MTCC 6576) to a maximum extent with MIC ranging from 62.5 to $250 \mu \mathrm{g} / \mathrm{mL}$. Crude extract of SCA 11 and SCA 13 exhibited potent scavenging activities against DPPH and ABTS radicals. The results from this study suggest that actinobacterial strains of Western Ghats are an excellent source of natural antimicrobial and antioxidant compounds. Further research investigations on purification, recovery, and structural characterization of the active compounds are to be carried out.
\end{abstract}

Keywords: Western Ghats; diversity; actinobacteria; antimicrobial; MRSA; antioxidants

\section{Introduction}

The quest for novel biologically active secondary metabolites from microorganisms continues to rise due to emergence of drug resistance in pathogens causing life threatening diseases around the globe [1]. Particularly, methicillin resistant Staphylococcus aureus (MRSA) and methicillin resistant Staphylococcus epidermidis (MRSE) strains are not only exposed to hospital-acquired infections but also to community-acquired infections [2]. The mortality and morbidity associated with these infections are largely affecting economic conditions of patients and hospitals [3]. Therefore, there 
is an urgent need for developing novel and effective antimicrobial agents to overcome or delay acquired resistance to existing drugs. Reactive oxygen species (ROS) play an important role as signaling molecules involved in mitogenesis. However, high generation of ROS during aerobic metabolism creates oxidative stress within the intracellular milieu causing oxidative damage to cells [4]. The oxidative stress caused is often associated with many human diseases including cancer, diabetes [5], cardiovascular [6], and neurodegenerative diseases [7]. In order to withstand the oxidative stress caused, cells or organisms make use of antioxidants, that are able to block or delay the damage caused by several possible mechanisms such as halting chain reactions, preventing the formation of free radicals, neutralizing the singlet oxygen molecule, promoting anti-oxidant enzymes, and inhibiting pro-oxidative enzymes [8]. Formation of free radicals can be prevented by antioxidant systems present within the cells. However, these defense mechanisms are insufficient to prevent the damages that arise, therefore exogenous antioxidants through dietary intake and supplements are required [9]. Natural antioxidants are found abundantly in metabolites produced by microorganisms. These products have consistently been considered as mainstay for drugs with various interesting biological activities [10]. They are considered to be an excellent scaffold for the formulation and development of antibiotics, antioxidants, immunomodulators, enzyme inhibitors, anticancer agents, plant growth hormones, and insect control agents [11]. With many improved techniques under combinatorial chemistry for high throughput findings of novel compounds, natural products from microbial sources have been screened extensively and gained much attention owing to their massive chemical and biological diversity [12]. Under various screening strategies, the rate of discovery of natural products has increased many folds, of which around 22,250 bioactive compounds are of microbial origin [13]. Among microorganisms, actinomycetes have contributed nearly $45 \%$ of all the reported metabolites [14].

A major group of natural products from microbial origin have been identified from organisms that inhabit the soil. Since soil itself is a mixture of minerals and organic matter, the filamentous bacteria are predominantly more present in the gaps between the soil particles than their unicellular counterparts [15]. Actinobacteria are ubiquitous in soils. They are responsible for biodegradation and biodeterioration processes in nature. Their flexile and proven abilities have prompted biologists to screen these organisms from unexplored niche habitats in order to obtain novel molecules [16].

Western Ghats of India is considered as one of the global biodiversity hotspots covering an area of $180,000 \mathrm{~km}^{2}$ and harbors numerous species of plants, animals, and microbes [17]. The unique biodiversity of Western Ghats is conserved and protected by wildlife sanctuaries, national parks, and biosphere reserves situated in states where hill ranges run through, like Karnataka, Gujarat, Tamil Nadu, Maharashtra, and Kerala [18]. The forest regions in Western Ghats are largely underexplored, though in recent times few studies were carried out for bioprospection. Ganesan et al. [19] reported larvicidal, ovicidal, and repellent activities of Streptomyces enissocaesilis (S12-17) isolated from Western Ghats of Tamil Nadu, India. Actinobacterial strains isolated from Western Ghats soil of Tamil Nadu were reported to produce antimicrobial compounds against range of pathogens [20]. In the present study, the forest range in Western Ghats of Karnataka was studied for microbial population and taxonomical identification of potential actinobacteria. An attempt was also made to characterize microbial diversity for the potential to produce antioxidants and antimicrobial compounds.

\section{Materials and Methods}

\subsection{Site, Sampling, Pre-Treatment, and Selective Isolation}

Soil samples were collected from different forest locations of Bisle Ghat and Virajpet in Western Ghats regions of Karnataka, India. The samples were collected from a depth of 15-25 cm in dry sterile insulated containers and stored aseptically at $4{ }^{\circ} \mathrm{C}$ until subjected to plating. Samples were air dried in a hot air oven (Equitron, India) at $50{ }^{\circ} \mathrm{C}$ for $72 \mathrm{~h}$. Pre-treated samples were ground aseptically with mortar and pestle and serially diluted up to $10^{-6}$ in 10 -fold dilution. The aliquots of each dilution $(100 \mu \mathrm{L})$ were spread evenly on starch casein agar (SCA, Himedia, India) plates in 
triplicates supplemented with cycloheximide $(30 \mu \mathrm{g} / \mathrm{mL})$ and nalidixic acid $(25 \mu \mathrm{g} / \mathrm{mL})$. The plates were incubated at $28 \pm 2{ }^{\circ} \mathrm{C}$ for 14 days. Emerging colonies with different morphological characters were selected and the purified strains were maintained on International Streptomyces Project (ISP-2, Himedia, India) agar slants and stored at $4{ }^{\circ} \mathrm{C}$ as stock for further use.

\subsection{Morphological Characterization of Isolates}

Morphological characteristics of isolates were assessed by scanning electron microscopy (SEM). Bacterial colonies were inoculated in ISP-2 medium and incubated at $28 \pm 2{ }^{\circ} \mathrm{C}$ for 7 days. Cells were centrifuged (Eppendorf, USA) at $8000 \times g$ for $10 \mathrm{~min}$ and pellet was resuspended in $2 \%-5 \%$ gluteraldehyde (Sigma, Burlington, VT, USA) prepared in 0.1M phosphate buffer, pH 7.2. After incubating samples for $30 \mathrm{~min}$, supernatant was discarded and pellet was resuspended in $1 \%$ osmium tetraoxide (Sigma, Burlington, VT, USA), incubated for $1 \mathrm{~h}$ and centrifuged at $5000 \times g$. To the pellet, sterile water was added and centrifuged twice for $10 \mathrm{~min}$ at $5000 \times \mathrm{g}$. For dehydration, the pellet was resuspended in 35\% ethanol for $10 \mathrm{~min}, 50 \%$ ethanol for $10 \mathrm{~min}, 75 \%$ ethanol for $10 \mathrm{~min}$, 95\% ethanol for $10 \mathrm{~min}$, and a final wash with $100 \%$ ethanol for $10 \mathrm{~min}$. For SEM analysis, sterilized aluminum stubs and cover slips were inserted into the SCA plates at an angle of about $45^{\circ} \mathrm{C}$. The plates with stubs and coverslips were incubated at $37^{\circ} \mathrm{C}$ for $24 \mathrm{~h}$ to check any contamination. After $24 \mathrm{~h}$, isolates were introduced along the line where the surface of the stub met the agar medium and incubated at $28 \pm 2{ }^{\circ} \mathrm{C}$ for 7 days. The stubs were then carefully removed and coated under vacuum, with a film of gold for 25-30 min and viewed on the scanning electron microscope (Zeiss Evo 40 EP, Germany).

\subsection{Molecular Identification and Phylogenetic Analysis}

The total genomic DNA of bacteria was extracted by phenol-chloroform method, quality checked by agarose gel electrophoresis and quantified using NanoDrop1000 (Thermo-Scientific, USA). The PCR amplification of $16 \mathrm{~S}$ rRNA gene was carried out with universal primers: 27F (5'-AGA GTT TGA TCC TGG CTC AG-3') and 1492R (5'- ACG GCT ACC TTG TTA CGA CTT-3') using the following conditions: initial denaturation temperature was set at $95^{\circ} \mathrm{C}$ for $5 \mathrm{~min}$, followed by 35 cycles at same temperature for $1 \mathrm{~min}$, primer annealing at $54^{\circ} \mathrm{C}$ for $1 \mathrm{~min}$, and primer extension at $72{ }^{\circ} \mathrm{C}$ for $2 \mathrm{~min}$. The reaction mixture was kept at $72{ }^{\circ} \mathrm{C}$ for 10 min subsequently and then cooled to $4{ }^{\circ} \mathrm{C}$. The PCR products were checked in $1.5 \%$ agarose gel and visualized in a UV transilluminator (Tarsons, India) and the gel imaging was done using a Gel documentation system (Bio-Rad, USA). The amplified PCR products were sequenced using same set of primers (27F' and 1492R') on Applied Biosystems 3130 Genetic Analyzer (Applied Biosystems, USA). The genetic relationship between the strains was determined by neighbor-joining tree algorithm method. The phylogenetic tree was constructed with a bootstrapped database containing 1000 replicates in MEGA 7.0 software (Mega, Raynham, MA, USA). The nearly complete $16 \mathrm{~S}$ rRNA consensus sequences were deposited in the GenBank database.

\subsection{Isolates Cultivation and Metabolites Extraction}

Pure isolates were subcultured in Tryptone Yeast Extract broth as seed medium (ISP-1 medium, Himedia, India) at $28^{\circ} \mathrm{C}$ for 2 weeks prior to fermentation process. The production medium, ISP-2 was autoclaved at $121^{\circ} \mathrm{C}$ and $1.5 \mathrm{~atm}$ for $15 \mathrm{~min}$. Fermentation was carried out in $750 \mathrm{~mL}$ of (in 7 nos. conical flasks $-1000 \mathrm{~mL}$ ) ISP-2 medium, shaking at $140 \mathrm{rev} \mathrm{min}{ }^{-1}$ for 14 days at $28^{\circ} \mathrm{C}$, inoculated with $250 \mu \mathrm{L}$ of seed medium. After incubation, the culture medium was split into mycelium and filtrate by centrifugation at $12,000 \times g$ for $15 \mathrm{~min}$. The cell free supernatant from each flask was subjected to extraction thrice with equal volume of ethyl acetate (Qualigens Fine Chemicals Pvt. Ltd., San Diego, USA) and the organic phase was concentrated by rotary vacuum evaporator (Hahn-Shin, Bucheon, South Korea) at $50{ }^{\circ} \mathrm{C}$. The crude concentrate was dried in a desiccator and suspended in methanol prior to bioactivity screening assays. 


\subsection{Antimicrobial Susceptibility Test}

\subsubsection{Disc Diffusion Assay}

Antimicrobial susceptibility assay was carried out by disc diffusion method against methicillin-resistance Staphylococcus aureus (MRSA ATCC 33591, MRSA ATCC NR-46071 and MRSA ATCC 46171), Gram-negative bacteria (Salmonella typhi (ATCC 25241) and Escherichia coli (ATCC 11775)) and fungus (Fusarium moniliforme (MTCC 6576)). Gentamicin and Nystatin discs were used as positive control. The sterile discs (6mm, Himedia) were impregnated with $30 \mu \mathrm{L}$ of crude extract dissolved in 0.5\% DMSO. Discs impregnated with 0.5\% DMSO (Qualigens Fine Chemicals Pvt. Ltd., San Diego, USA) were used as solvent control. The plates were left for $30 \mathrm{~min}$ at $4{ }^{\circ} \mathrm{C}$ to allow the diffusion of extracts before they were incubated for $24-48 \mathrm{~h}$ at $37^{\circ} \mathrm{C}$. The clear zones of inhibition observed around discs suggested antagonistic activity against test organisms and diameter of inhibition zones were measured subsequently. The test was performed in triplicate.

\subsubsection{Minimum Inhibitory Concentration (MIC)}

The minimum inhibitory concentration assay was determined by micro broth dilution method as previously reported by Siddharth and Rai [21]. The serially diluted fraction of extracts with sterile Mueller Hinton broth (Himedia, India) was added to pre coated microbial cultures in 96-well micro titer plates to give a final concentration of $1-3.8 \mu \mathrm{g} / \mathrm{mL}$. The titer plate was incubated for $24 \mathrm{~h}$ at $37^{\circ} \mathrm{C}$. The lowest concentration of extract which completely inhibited the bacterial growth (no turbidity) was considered as MIC. Each test was done in triplicate.

\subsection{Antioxidant Assays}

2.6.1. 2,2-diphenyl-1-picrylhydrazyl Radical Scavenging activity (DPPH)

DPPH radical scavenging activity of crude extracts was examined based on a previously described method by Siddharth and Rai [22]. Crude extracts at varying concentrations $(7.81-1000 \mu \mathrm{g} / \mathrm{mL})$ were reacted with freshly prepared DPPH in methanol (60 mM, Sigma, USA). Reaction mixture was incubated at room temperature for $30 \mathrm{~min}$ in the dark prior to the measurement of absorbance at $520 \mathrm{~nm}$. The radical scavenging activity was expressed as $\mathrm{IC}_{50}(\mu \mathrm{g} / \mathrm{mL})$. The percentage scavenging of DPPH radicals was computed by the following equation:

$$
\text { DPPH scavenging effect }(\%)=\left[\left(\mathrm{A}_{\mathrm{o}}-\mathrm{A}_{1}\right) / \mathrm{A}_{\mathrm{o}}\right] \times 100
$$

where, $\mathrm{A}_{\mathrm{o}}=$ Absorbance of control, $\mathrm{A}_{1}=$ Absorbance of crude extracts. Trolox (Sigma) was used as a reference compound whereas methanol was used as blank.

2.6.2. 2,2'-Azino-bis(3-ethylbenzothiazoline-6-sulfonic acid) Radical Scavenging Activity (ABTS)

ABTS radical scavenging activity was performed according to the method developed by Ser et al. [23] with slight modifications. Crude extracts at concentrations $(7.81-1000 \mu \mathrm{g} / \mathrm{mL})$ were mixed with ABTS (Sigma, USA) cation complex and incubated in dark at room temperature for $30 \mathrm{~min}$. The absorbance was measured at $415 \mathrm{~nm}$. The radical scavenging activity was expressed as $\mathrm{IC}_{50}$ $(\mu \mathrm{g} / \mathrm{mL})$. The percentage inhibition of $\mathrm{ABTS}^{*+}$ radicals were computed by using following equation:

$$
\text { ABTS }^{*+} \text { scavenging effect }(\%)=\left[\left(\mathrm{A}_{\mathrm{o}}-\mathrm{A}_{1}\right) / \mathrm{A}_{\mathrm{o}}\right] \times 100
$$

where, $\mathrm{A}_{\mathrm{o}}=$ Absorbance of control, $\mathrm{A}_{1}=$ Absorbance of crude extracts. Trolox (Sigma) was used as a positive reference.

\section{Results and Discussion}

Soil is among the most productive habitat colonized by a large number of organisms. The rhizosphere soil in the vicinity of plant roots provides essential nutrients in the form of exudates 
which favors the growth of microbial communities [24]. Soil microbes are a major source of a number of natural products including clinical important antibiotics, immunomodulators, enzyme inhibitors, antioxidants, anti-tumor and anticancer agents. Actinobacteria are abundant in soil, species of Streptomyces in particular represent the dominance over other microbes present in soil and play a vital role in recycling of materials and production of important metabolites [25]. Rare actinobacteria genera such as Nocardia, Nocardiopsis, and Nocardioides are also encountered in soils, though their presence is subjected to conditions of soil such as salinity and alkalinity [26]. The rapid emergence of drug resistant pathogens urges the exploration of new niche habitats for the isolation of new microbial species which can contribute to the uncovering of novel, safe, effective, and broad spectrum bioactive compounds [27].

\subsection{Isolation, Morphological, and Molecular Characterization of Actinobacterial Isolates}

In this study, from forest soil of Bisle Ghat and Virajpet of Western Ghats region of Karnataka, we targeted the isolation of different genera of actinobacteria in search of new natural products (Table 1 ). A total of 32 actinobacterial isolates were recovered on Starch casein agar and Actinomycetes isolation agar. Of them, seven isolates grown on starch casein agar medium showing marked antimicrobial activity against test organisms in primary screening were characterized on the basis of cultural, morphological, and molecular characteristics. The colonies of isolates revealed diverse morphological appearances with varied spore color, aerial and substrate mycelium, and colony morphology (Table 2 and Figure 1). Scanning electron microscope examination showed chains of smooth and spiny spores in oval, round, and spiral ornamentation (Figure 2). The molecular identification of isolates by amplification of 16S-rRNA gene was done by using universal primers $27 \mathrm{~F}^{\prime}$ and $1492 \mathrm{R}^{\prime}$ (Figure S1). In 16S-rRNA sequencing, alignment of the nucleotide sequences of strain S1A, SS4, SS5, SS6, and SCA35 exhibited a similarity of $98.32 \%, 99.71 \%, 99.70 \%, 99.72 \%$, and $99.35 \%$ with closely related Streptomyces species, respectively. The strain SCA11 was considered to represent a species of the genus Nocardiopsis, since it was closely related to Nocardiopsis species with $98.99 \%$ sequence similarity. The nucleotide sequence of strain SCA13 showed $98.28 \%$ similarity with the closely related Nocardioides sp. (Table 3). The phylogenetic relatedness of strains with their closely related species obtained by neighbor-joining method is shown in Figures 3-5.

Table 1. Actinobacterial isolates and sampling areas in Western Ghats regions of Karnataka, India.

\begin{tabular}{|c|c|c|c|c|c|}
\hline Name & Sample Code & Sampling Area & Latitude (N) & Longitude (E) & Elevation (m) \\
\hline Streptomyces Sp. & S1A & $\begin{array}{c}\text { Bisle Ghat, Hassan } \\
\text { District }\end{array}$ & $12^{\circ} 71^{\prime} 88.04^{\prime \prime}$ & $75^{\circ} 68^{\prime} 70.02^{\prime \prime}$ & 802 \\
\hline Streptomyces Sp. & SS4 & $\begin{array}{c}\text { Bisle Ghat, Hassan } \\
\text { District }\end{array}$ & $12^{\circ} 72^{\prime} 00.89^{\prime \prime}$ & $75^{\circ} 68^{\prime} 41.42^{\prime \prime}$ & 752 \\
\hline Streptomyces Sp. & SS5 & $\begin{array}{c}\text { Bisle Ghat, Hassan } \\
\text { District }\end{array}$ & $12^{\circ} 71^{\prime} 24.30^{\prime \prime}$ & $75^{\circ} 68^{\prime} 04.74^{\prime \prime}$ & 710 \\
\hline Streptomyces Sp. & SS6 & $\begin{array}{l}\text { Virajpet, Madikeri } \\
\text { District }\end{array}$ & $12^{\circ} 19^{\prime} 75.83^{\prime \prime}$ & $75^{\circ} 79^{\prime} 52.93^{\prime \prime}$ & 885 \\
\hline Streptomyces Sp. & SCA35 & $\begin{array}{c}\text { Virajpet, Madikeri } \\
\text { District }\end{array}$ & $12^{\circ} 18^{\prime} 83.38^{\prime \prime}$ & $75^{\circ} 83^{\prime} 06.79^{\prime \prime}$ & 864 \\
\hline Nocardiopsis Sp. & SCA11 & $\begin{array}{l}\text { Virajpet, Madikeri } \\
\text { District }\end{array}$ & $12^{\circ} 21^{\prime} 21.64^{\prime \prime}$ & $75^{\circ} 80^{\prime} 24.84^{\prime \prime}$ & 830 \\
\hline Nocardioides Sp. & SCA13 & $\begin{array}{c}\text { Virajpet, Madikeri } \\
\text { District }\end{array}$ & $12^{\circ} 18^{\prime} 47.27^{\prime \prime}$ & $75^{\circ} 76^{\prime} 24.17^{\prime \prime}$ & 798 \\
\hline
\end{tabular}


Table 2. Morphological characteristics of isolated actinobacterial strains.

\begin{tabular}{cccccc}
\hline Isolate & Medium & $\begin{array}{c}\text { Diffusible } \\
\text { Pigment }\end{array}$ & $\begin{array}{c}\text { Colony } \\
\text { Morphology }\end{array}$ & $\begin{array}{c}\text { Aerial } \\
\text { Mycelium }\end{array}$ & $\begin{array}{c}\text { Substrate } \\
\text { Mycelium }\end{array}$ \\
\hline Streptomyces Sp. S1A & SCA & None & Powdery & White & Cream \\
Streptomyces Sp. SS4 & SCA & None & Cottony & Dark Grey & Grey \\
Streptomyces Sp. SS5 & SCA & None & Cottony & Grey & Cream \\
Streptomyces Sp. SS6 & SCA & Pink & Rough & Pale red & Pink \\
Streptomyces Sp. SCA35 & SCA & None & Powdery & White & Cream \\
Nocardiopsis Sp. SCA11 & SCA & None & Powdery & Cream & Light brown \\
Nocardioides Sp. SCA13 & SCA & None & Raised & White & White \\
\hline
\end{tabular}

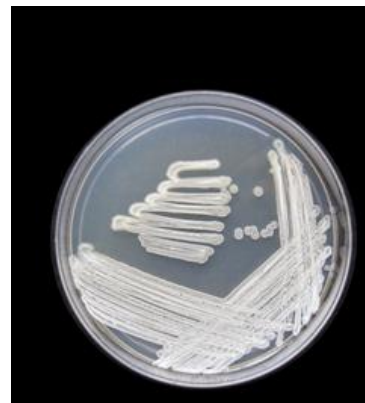

Streptomyces Sp. S1A

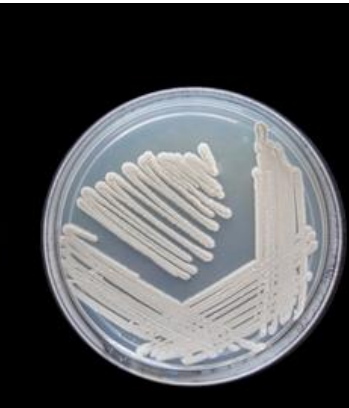

Streptomyces Sp.SS4

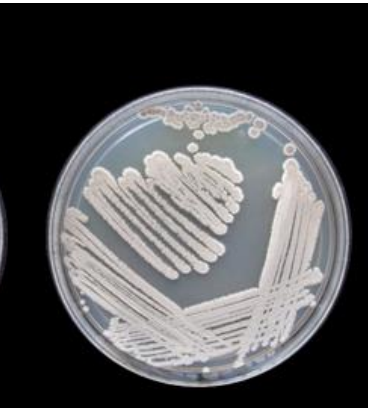

Streptomyces Sp.SS5

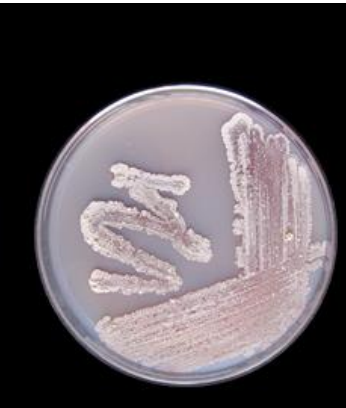

Streptomyces Sp. SS6

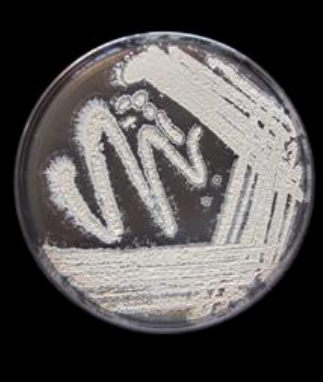

Nocardiopsis Sp. SCA11

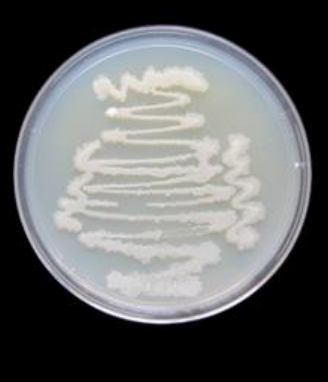

Nocardioides Sp. SCA13

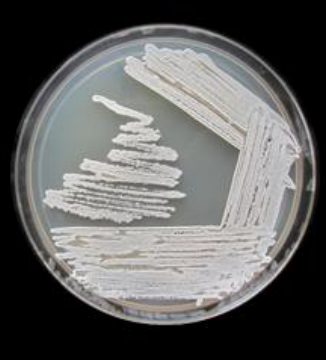

Streptomyces Sp. SCA35

Figure 1. Morphological characterization of actinobacterial isolates on starch casein agar plates.

Table 3. Molecular identification (based on 16S rRNA amplification) of actinobacterial strains isolated from Western Ghats.

\begin{tabular}{cccc}
\hline Source & Organism & GenBank Accession No & \% Similarity \\
\hline Soil & Streptomyces Sp. S1A & KU921223 & $98.32 \%$ \\
Soil & Streptomyces Sp. SS4 & MF668120 & $99.71 \%$ \\
Soil & Streptomyces Sp. SS5 & MF925722 & $99.70 \%$ \\
Soil & Streptomyces Sp. SS6 & MF925723 & $99.72 \%$ \\
Soil & Streptomyces Sp. SCA35 & MN176654 & $99.35 \%$ \\
Soil & Nocardiopsis Sp. SCA11 & MG934272 & $98.99 \%$ \\
Soil & Nocardioides Sp. SCA13 & MG934273 & $98.28 \%$ \\
\hline
\end{tabular}




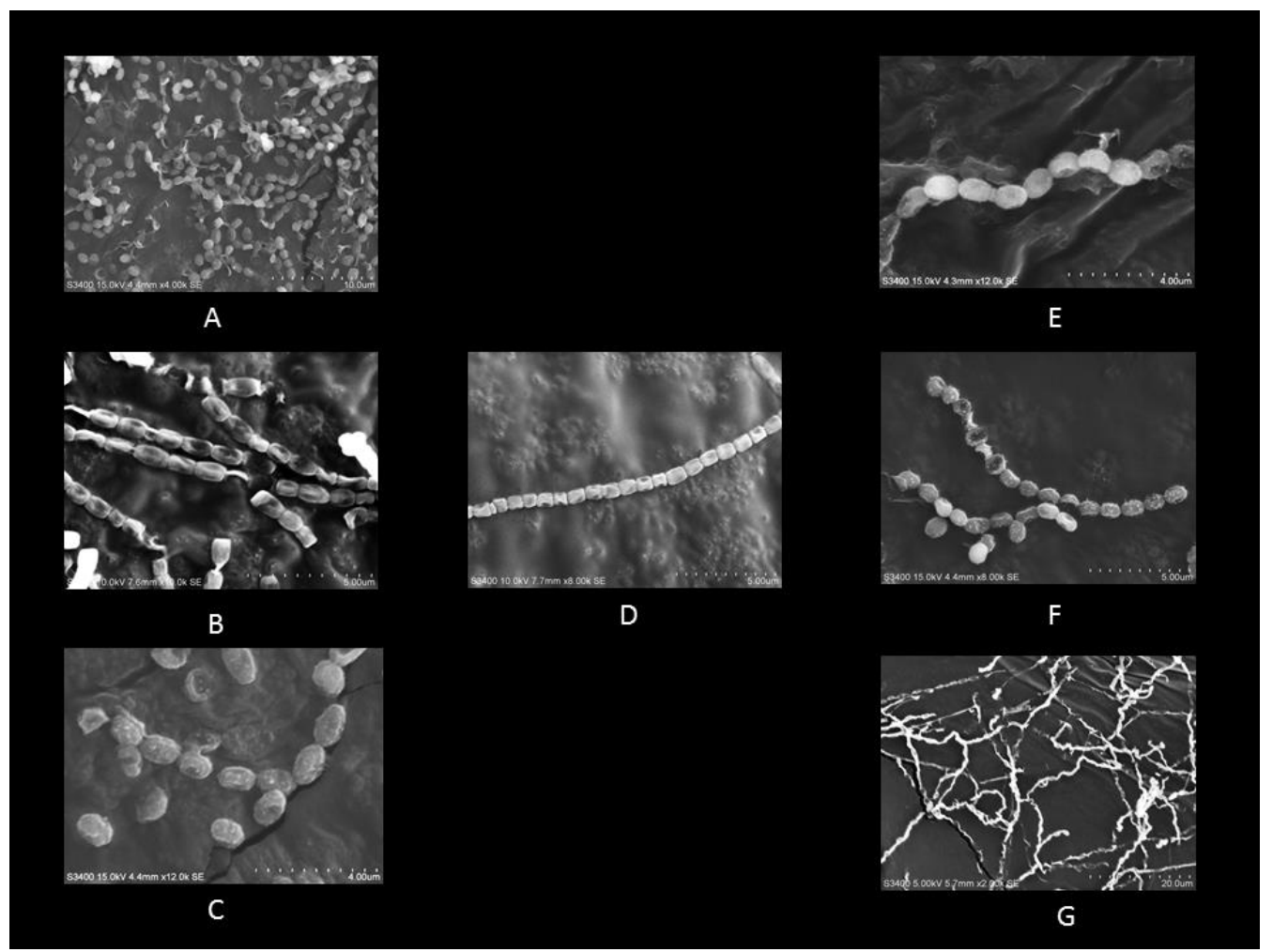

Figure 2. Scanning electron micrograph of strains (A) S1A, (B) SCA11, (C) SS4, (D) SS5, (E) SS6, (F) SCA35, (G) SCA13; scale bar represents $5 \mu \mathrm{m}$.

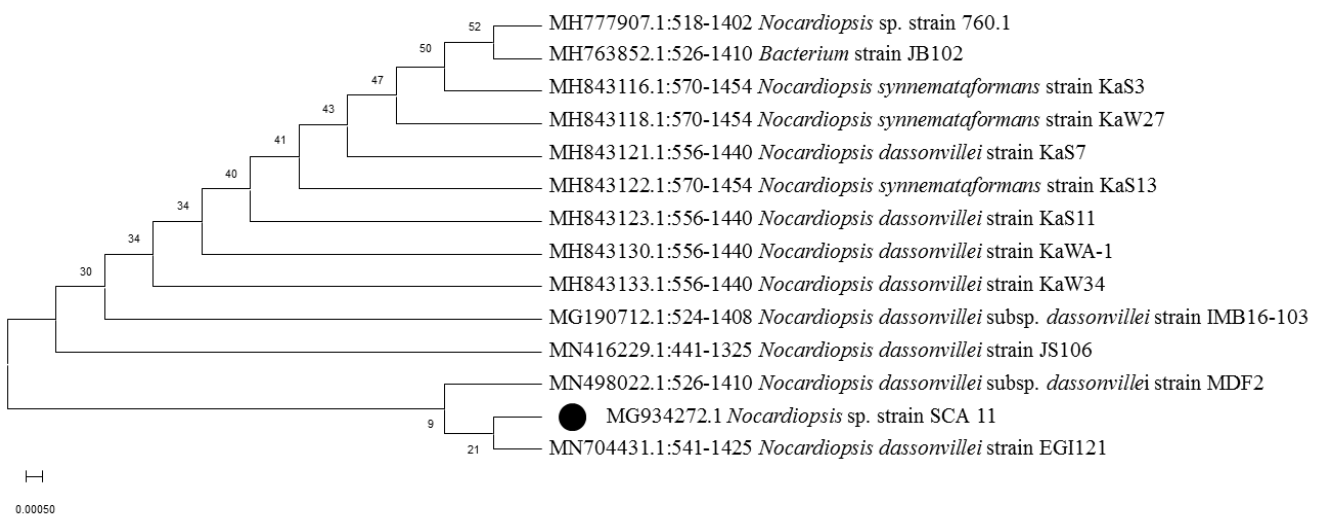

Figure 3. Phylogenetic analysis of isolate Nocardiopsis sp. strain SCA11. Neighbor-joining phylogenetic tree showing evolutionary relationship of selected isolate based on 16S r-RNA sequence alignments. Bootstrap values at the nodes indicate collated values based on 1000 resampled datasets. Bar indicates 0.0005 substitutions per nucleotide position.

\subsection{Antimicrobial and Antioxidant Potential of Isolates}

In this study, all seven isolates showed antibacterial activity against at least one test bacterium. All isolates inhibited MRSA strains significantly (MRSA ATCC 33591, MRSA ATCC NR-46071, and MRSA ATCC 46171), whereas showed less inhibition potential against Gram-negative bacteria Salmonella typhi (ATCC 25241) and Escherichia coli (ATCC 11775). The isolates namely S1A, SS5, SCA35, and SCA 11 inhibited Fusarium moniliforme (MTCC 6576) to a maximum extent (Figure 6). The minimum inhibition concentration (MIC) ranges from 15.62 to $125 \mu \mathrm{g} / \mathrm{mL}$ for MRSA strains, $125-500 \mu \mathrm{g} / \mathrm{mL}$ for Gram-negative bacteria, and $62.5-250 \mu \mathrm{g} / \mathrm{mL}$ for fungi (Table 4). Numerous studies have reported antimicrobial activity of actinobacterial species. Sengupta et al. [28] reported 
potential antimicrobial activity of three isolates against Pseudomonas aueroginosa, Enterobacter aueroginosa, Salmonella typhi, Salmonella typhimurium, Escherichia coli, Bacillus subtilis, and Vibrio cholera. Satheeja and Jebakumar [29] reported isolation of Streptomcyes species from a mangrove ecosystem for antibacterial activity against clinical isolates of MRSA, methicillin-susceptible Staphylococcus aureus (MSSA), and Salmonella typhi. Vu et al. [30] reported antimicrobial activity of Streptomyces cavourensis YBQ59 against methicillin-resistant Staphylococcus aureus ATCC 33591 and methicillin-resistant Staphylococcus epidermidis ATCC 358984. Dashti et al. [31] reported the co-cultivation of Actinokineospora sp.EG49 and Nocardiopsis sp.RV163 and metabolites produced were tested for antimicrobial activity against the range of pathogens. The bioactive metabolite from Streptomyces cyaneofuscatus M-169 showed significant inhibition of Gram-positive bacteria with MIC value of $0.03 \mu \mathrm{g} / \mathrm{mL}$ [32]. It has been shown that actinobacterial isolates from Western Ghats exhibit antimicrobial activity. The Streptomyces species from Agumbe [33], Streptomyces sp. RAMPP-065 from Kudremukh [34], and Streptomyces sp. GOS1 isolated from Western Ghats of Agumbe, Karnataka [35] exhibited remarkable antimicrobial activity. In earlier studies, Streptomyces species isolated from Kodachadri were found to possess antifungal activity [33]. Each extract was evaluated for scavenging activity against DPPH and ABTS radicals for antioxidant activity. Crude extract of strain SCA11 showed potent scavenging activity against DPPH radicals with $\mathrm{IC}_{50}(\mu \mathrm{g} / \mathrm{mL}) 30.91 \pm 0.25$, whereas SCA13 showed remarkable scavenging activity against ABTS radicals with $\mathrm{IC}_{50}(\mu \mathrm{g} / \mathrm{mL}) 37.91 \pm 0.17$. Trolox as a standard showed significant activity with $\mathrm{IC}_{50}(\mu \mathrm{g} / \mathrm{mL}) 11.07 \pm 0.06$ and $9.87 \pm 0.01$ against DPPH and ABTS radicals, respectively (Table 5). Similar studies were carried out for the detection of compounds with antioxidant activity from Streptomyces spp., dihydroherbimycin A [36], 5-(2,4-dimethylbenzyl)pyrrolidin-2-one [37]. Ser et al. [38] reported antioxidant activity of pyrrolo[1,2-a]pyrazine-1,4-dione, hexahydro extracted from Streptomyces mangrovisoli, a novel Streptomyces species isolated from a mangrove forest in Malaysia. Narendhran et al. [39] successfully reported antioxidant potential of phenol, 2,4-bis(1,1-dimethylethyl) in Streptomyces cavouresis KUV39 isolated from vermicompost samples. Tian et al. [40] reported antioxidant, antifungal, and antibacterial activity of $p$-Terphenyls isolated from halophilic actinobacteria Nocardiopsis gilva YIM 90087. Current findings indicated the bioactive potential of actinobacterial isolates from Western Ghats region of Karnataka. The isolates were found to possess significant antimicrobial activity against Gram-positive MRSA bacteria, Gram-negative bacteria, and fungal pathogens. They also exhibited potent scavenging activity against DPPH and ABTS radicals suggesting their antioxidant potential. It is anticipated that findings of the study will be useful in the discovery of novel species of actinobacteria for a potential source of bioactive compounds from underexplored environments.

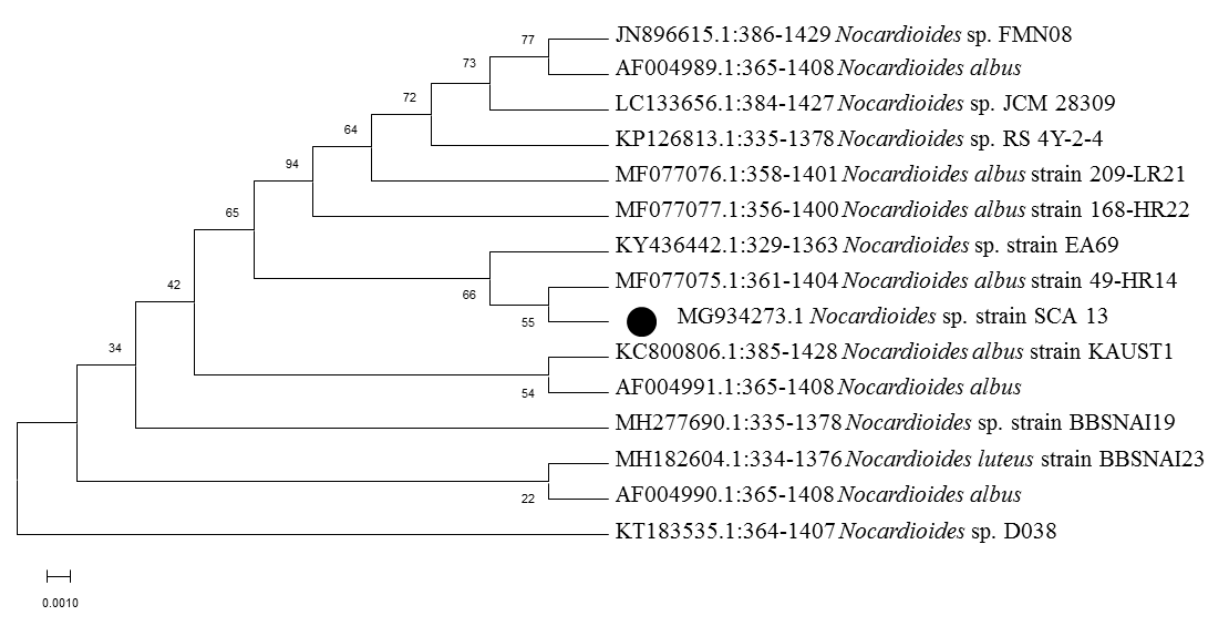

Figure 4. Phylogenetic analysis of isolate Nocardioides sp. strain SCA13. Neighbor-joining phylogenetic tree showing evolutionary relationship of selected isolate based on 16S r-RNA sequence alignments. Bootstrap values at the nodes indicate collated values based on 1000 resampleddatasets. Bar indicates 0.001 substitutions per nucleotide position. 


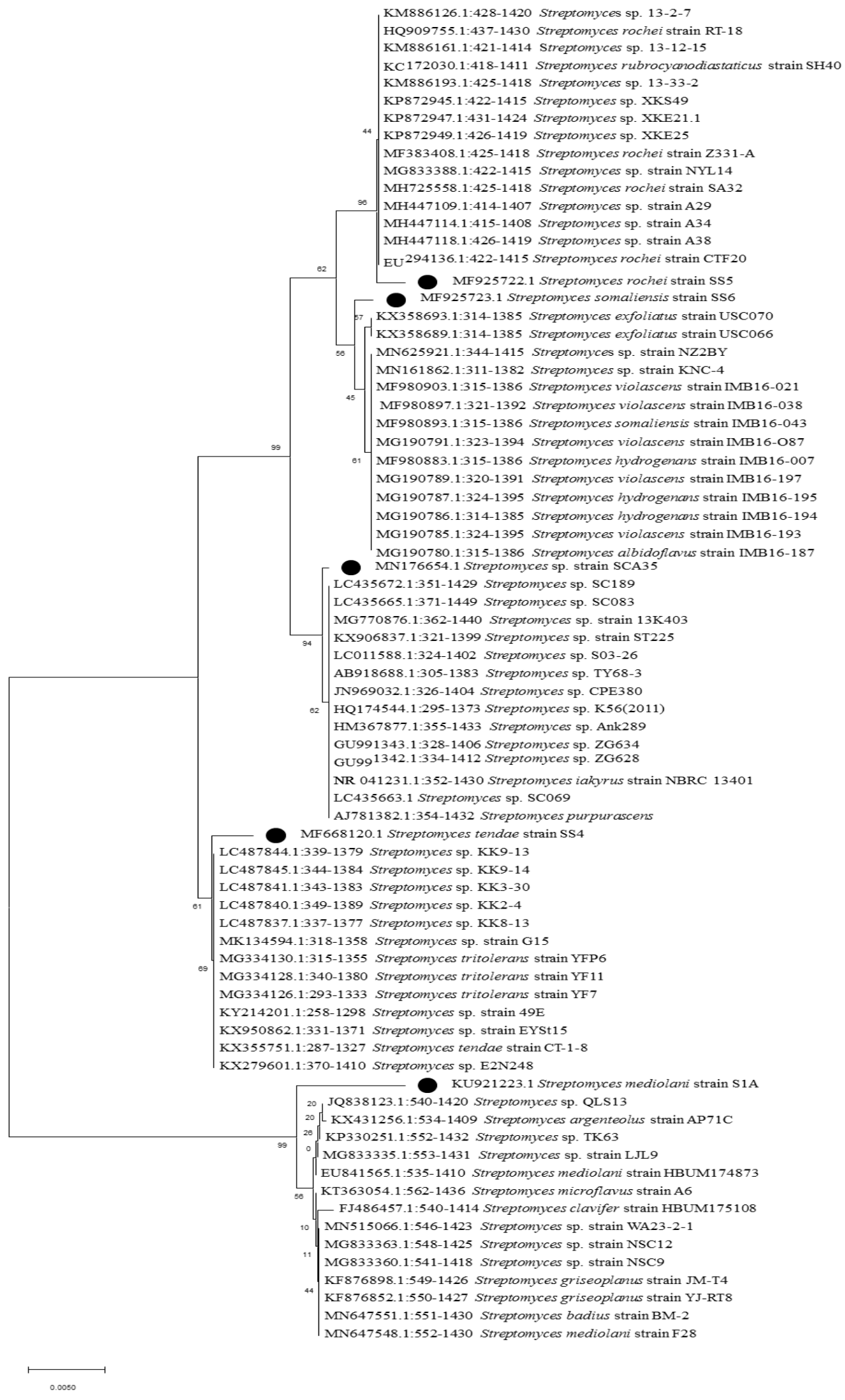

Figure 5. Neighbor-joining phylogenetic tree showing evolutionary relationship between isolates S1A, SS4, SS5, SS6, and SCA35 based on 16S r-RNA sequence alignments. Bootstrap values at the nodes indicate collated values based on 1000 resampled datasets. Bar indicates 0.005 substitutions per nucleotide position. 

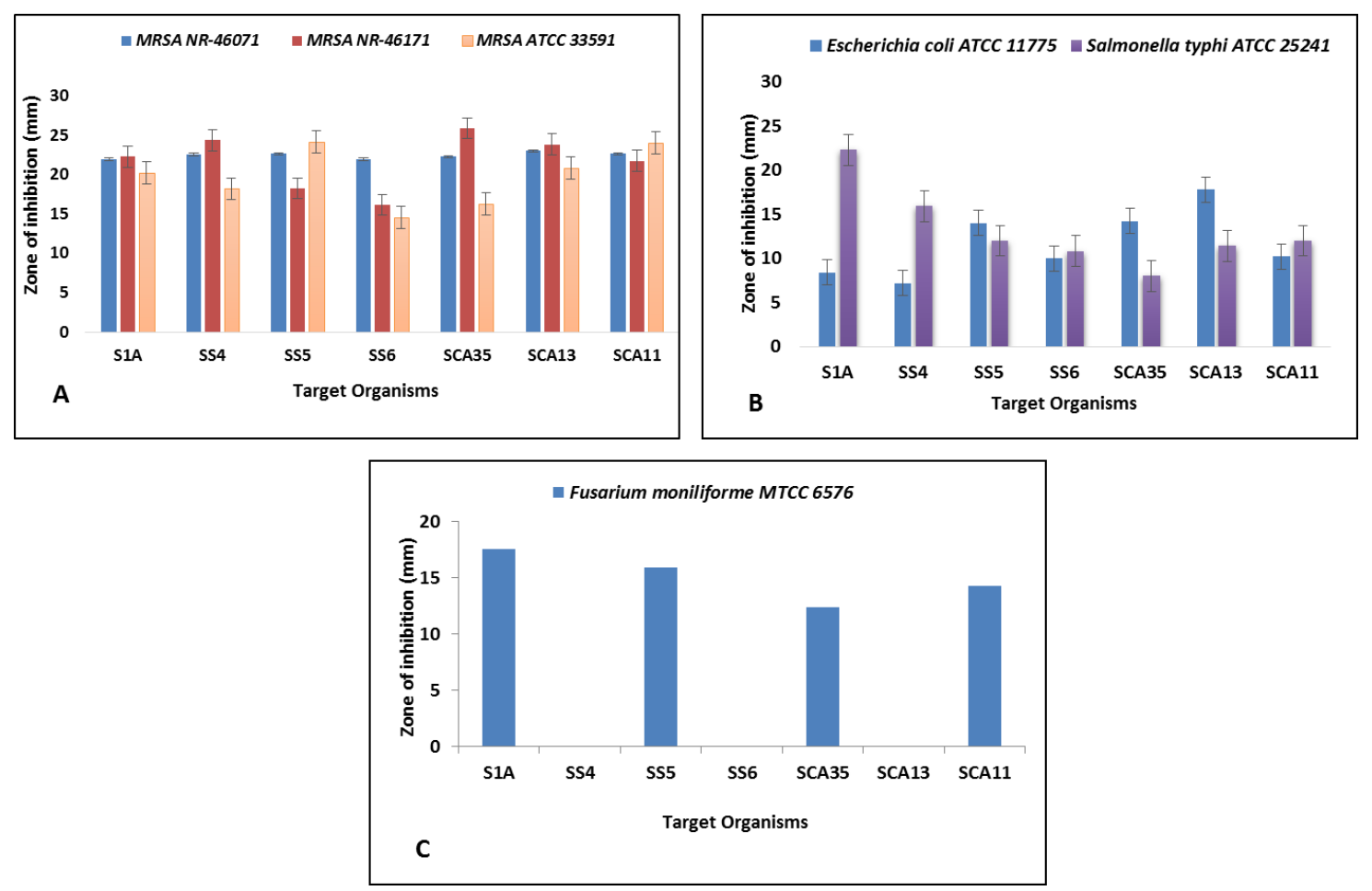

Figure 6. Antimicrobial activity of actinobacterial isolates against (A) MRSA ATCC NR 46071, MRSA ATCC NR 46171, and MRSA ATCC 33591 (B) Escherichia coli ATCC 11775 and Salmonella typhi ATCC 25241, (C) Fusarium moniliforme MTCC 6576.

Table 4. Minimum inhibitory concentration (MIC in $\mu \mathrm{g} / \mathrm{mL}$ ) of actinobacterial isolates against pathogenic test organisms.

\begin{tabular}{|c|c|c|c|c|c|c|}
\hline \multirow{3}{*}{ Organisms } & \multicolumn{6}{|c|}{ Minimum Inhibition Concentration $(\mu \mathrm{g} / \mathrm{mL})$} \\
\hline & \multicolumn{6}{|c|}{ Test Organisms } \\
\hline & $\begin{array}{c}\text { MRSA ATCC } \\
\text { NR-46071 }\end{array}$ & $\begin{array}{l}\text { MRSA ATCC } \\
\text { NR-46171 }\end{array}$ & $\begin{array}{c}\text { MRSA } \\
\text { ATCC } 33591\end{array}$ & $\begin{array}{l}\text { Salmonella typhi } \\
\text { ATCC } 25241\end{array}$ & $\begin{array}{l}\text { Escherichia coli } \\
\text { ATCC } 11775\end{array}$ & $\begin{array}{c}\text { Fusarium } \\
\text { moniliforme } \mathrm{MTCC} \\
6576\end{array}$ \\
\hline Streptomyces Sp. S1A & 15.62 & 15.62 & 62.5 & 125 & $>500$ & 62.5 \\
\hline Streptomyces Sp. SS4 & 62.5 & 31.25 & 125 & 250 & $>500$ & - \\
\hline Streptomyces Sp. SS5 & 31.25 & 125 & 15.62 & 250 & 250 & 125 \\
\hline Streptomyces Sp. SS6 & 31.25 & 62.5 & 62.5 & 250 & 125 & - \\
\hline Streptomyces Sp. SCA35 & 62.5 & 15.62 & 125 & $>500$ & 125 & 250 \\
\hline Nocardiopsis Sp. SCA11 & 31.25 & 15.62 & 31.25 & 250 & $>500$ & 125 \\
\hline Nocardioides Sp. SCA13 & 62.5 & 62.5 & 125 & 250 & 125 & - \\
\hline
\end{tabular}

Table 5. Comparison of $\mathrm{IC}_{50}(\mu \mathrm{g} / \mathrm{mL})$ of crude extracts and trolox for DPPH and ABTS radical scavenging activity.

\begin{tabular}{ccc}
\hline \multirow{2}{*}{ Isolates } & \multicolumn{2}{c}{$\begin{array}{c}\text { IC }_{50}(\mu \mathrm{g} / \mathrm{mL}) \\
\text { Crude Extracts }\end{array}$} \\
\cline { 2 - 3 } & DPPH & ABTS \\
\hline Streptomyces Sp. S1A & $189.40 \pm 0.12$ & $156.81 \pm 0.06$ \\
Streptomyces Sp. SS4 & $98.29 \pm 0.32$ & $123.48 \pm 0.13$ \\
Streptomyces Sp. SS5 & $86.45 \pm 0.04$ & $114.87 \pm 0.29$ \\
Streptomyces Sp. SS6 & $114.15 \pm 0.03$ & $164.04 \pm 0.07$ \\
Streptomyces Sp. SCA35 & $65.86 \pm 0.49$ & $49.11 \pm 0.73$ \\
Nocardiopsis Sp. SCA11 & $30.91 \pm 0.25$ & $48.24 \pm 0.30$ \\
Nocardioides Sp. SCA13 & $42.30 \pm 0.10$ & $37.91 \pm 0.17$ \\
\hline Trolox (Standard) & $11.07 \pm 0.06$ & $9.87 \pm 0.01$ \\
\hline
\end{tabular}




\section{Conclusions}

The present study was successful in determining the diversity and bioactive potential of actinobacterial isolates from Western Ghats region of Karnataka. Relatively underexplored forest regions of Western Ghats of Karnataka are found to be promising resources for the discovery of natural bioactive metabolites. The isolates showed significant antimicrobial activity against pathogenic Gram-positive MRSA bacteria, Gram-negative bacteria, and fungi. They were also found to possess antioxidant potential. Our studies encourage the exploration of diverse ecosystems for the isolation of new species for novel and biologically active compounds. Further studies are under progress to purify and characterize the crude extracts that may result in the economic production of bioactive compounds for pharmaceutical applications.

Supplementary Materials: Supplementary materials can be found at http://www.mdpi.com/2076-2607/8/2/225/s1.

Author Contributions: Conceptualization, S.S., R.R.V., W.J. and M.S.; Methodology, S.S. and R.R.V.; Formal analysis, S.S. and R.R.V.; Investigation, S.S., Original Draft Preparation, S.S. and R.R.V.; Writing-Reviewing and Editing, S.S., R.R.V., W.J. and M.S.; Visualization, S.S. and R.R.V.; Supervision, R.R.V. All authors have read and agreed to the published version of the manuscript.

Funding: This research was funded by India Council of Medical Research, New Delhi (ICMR-SRF/AMR/FELLOWSHIPS/5/2019-ECD-II, dated: 27.06.2019).

Acknowledgments: The authors would like to acknowledge the facilities provided by University of Mysore. The authors gratefully acknowledge the financial support grant to Mr. Saket Siddharth, ICMR-SRF from India Council of Medical Research, New Delhi (ICMR-SRF/AMR/FELLOWSHIPS/5/2019-ECD-II, dated: 27.06.2019).

Conflicts of Interest: The authors declare that they have no conflict of interest. The funders had no role in the design of the study; in the collection, analyses, or interpretation of data; in the writing of the manuscript, or in the decision to publish the results.

\section{References}

1. Liu, H.; Xiao, L.; Wei, J.; Schmitz, J.C.; Liu, M.; Wang, C.; Cheng, L.; Wu, N.; Chen, L.; Zhang, Y.; et al. Identification of Streptomyces sp. nov. WH26 producing cytotoxic compounds isolated from marine solar saltern in China. World J. Microbiol. Biotechnol. 2013, 29, 1271-1278. [CrossRef]

2. David, M.Z.; Daum, R.S. Community-associated methicillin-resistant Staphylococcus aureus: Epidemiology and clinical consequences of an emerging epidemic. Clin. Microbiol. Rev. 2010, 23, 616-687. [CrossRef] [PubMed]

3. Chalasani, A.G.; Dhanarajan, G.; Nema, S.; Sen, R.; Roy, U. An antimicrobial metabolite from Bacillus sp.: Significant activity against pathogenic bacteria including multidrug-resistant clinical strains. Front. Microbiol. 2015, 6, 1335. [CrossRef] [PubMed]

4. Torres, M.A.; Jones, J.D.; Dangl, J.L. Reactive oxygen species signalling in response to pathogens. Plant. Physiol. 2006, 141, 373-378. [CrossRef] [PubMed]

5. Giacco, F.; Brownlee, M. Oxidative stress and diabetic complications. Circ. Res. 2010, 107, 1058-1070. [CrossRef] [PubMed]

6. Fearon, I.M.; Faux, S.P. Oxidative stress and cardiovascular disease: Novel tools give (free) radical insight. J. Mol. Cell. Cardiol. 2009, 47, 372-381. [CrossRef] [PubMed]

7. Barnham, K.J.; Masters, C.L.; Bush, A.I. Neurodegenerative diseases and oxidative stress. Nat. Rev. Drug Discov. 2004, 3, 205-214. [CrossRef]

8. Zhang, H.; Tsao, R. Dietary polyphenols, oxidative stress and antioxidant and anti-inflammatory effects. Curr. Opin. Food Sci. 2016, 8, 33-42. [CrossRef]

9. Carocho, M.; Ferreira, I.C. A review on antioxidants, prooxidants and related controversy: Natural and synthetic compounds, screening and analysis methodologies and future perspectives. Food Chem. Toxicol. 2013, 51, 15-25. [CrossRef]

10. Thompson, C.C.; Kruger, R.H.; Thompson, F.L. Unlocking marine biotechnology in the developing world. Trends Biotechnol. 2017, 35, 1119-1121. [CrossRef]

11. Berdy, J. Thoughts and facts about antibiotics: Where we are now and where we are heading. J. Antibiot. 2012, 65, 385-395. [CrossRef] [PubMed] 
12. Qin, S.; Xing, K.; Jiang, J.H.; Xu, L.H.; Li, W.J. Biodiversity, bioactive natural products and biotechnological potential of plant-associated endophytic actinobacteria. Appl. Microbiol. Biotechnol. 2011, 89, 457-473. [CrossRef] [PubMed]

13. Manivasagan, P.; Venkatesan, J.; Sivakumar, K.; Kim, S.K. Pharmaceutically active secondary metabolites of marine actinobacteria. Microbiol. Res. 2013, 169, 262-278. [CrossRef] [PubMed]

14. Nagpure, A.; Choudhary, B.; Kumar, S.; Gupta, R.K. Isolation and characterization of chitinolytic Streptomyces sp. MT7 and its antagonism towards wood-rotting fungi. Ann. Microbiol. 2014, 64, 531-541. [CrossRef]

15. Che, Q.; Zhu, T.; Qi, X.; Mandi, A.; Mo, X.; Li, J. Hybrid isoprenoids from a reed rhizosphere soil derived actinomycete Streptomyces sp. CHQ-64. Org. Lett. 2012, 14, 3438-3441. [CrossRef]

16. Ibeyaima, A.; Rana, J.; Dwivedi, A.K.; Saini, N.; Gupta, S.; Sarethy, I.P. Pseudonocardiaceae sp. TD-015 from the Thar Desert, India: Antimicrobial activity and identification of antimicrobial compounds. Curr. Bioact. Compd. 2017, 14, 112-118. [CrossRef]

17. Gautham, S.A.; Shobha, K.S.; Onkarappa, R.; Kekuda, P.T.R. Isolation, characterization and antimicrobial potential of Streptomyces species from Western Ghats of Karnataka, India. Res. J. Pharm. Technol. 2012, 5, 233-238.

18. Nampoothiri, M.K.; Ramkumar, B.; Pandey, A. Western Ghats of India: Rich source of microbial diversity. J. Sci. Ind. Res. 2013, 72, 617-623.

19. Ganesan, P.; Anand, S.; Sivanandhan, S.; David, R.H.A.; Paulraj, M.G.; Al-Dhabi, N.A.; Ignacimuthu, S. Larvicidal, ovicidal and repellent activities of Streptomyces enissocaesilis (S12-17) isolated from Western Ghats of Tamil Nadu, India. J. Entomol. 2018, 6, 1828-1835.

20. Ganesan, P.; Reegan, A.D.; David, R.H.A.; Gandhi, M.R.; Paulraj, M.G.; Al-Dhabi, N.A.; Ignacimuthu, S. Antimicrobial activity of some actinomycetes from Western Ghats of Tamil Nadu, India. Alexandria J. 2017, 53, 101-110. [CrossRef]

21. Siddharth, S.; Vittal, R.R. Evaluation of antimicrobial, enzyme inhibitory, antioxidant and cytotoxic activities of partially purified volatile metabolites of marine Streptomyces sp. S2A. Microorganisms 2018, 6, 72. [CrossRef]

22. Siddharth, S.; Vittal, R.R. Isolation and characterization of bioactive compounds with antibacterial, antioxidant and enzyme inhibitory activities from marine-derived rare actinobacteria, Nocardiopsis sp. SCA21. Microb. Pathog. 2019, 103775. [CrossRef] [PubMed]

23. Ser, H.L.; Tan, L.T.; Palanisamy, U.D.; Abd Malek, S.N.; Yin, W.F.; Chan, K.G. Streptomyces antioxidans sp. nov., a novel mangrove soil actinobacterium with antioxidative and neuroprotective potentials. Front. Microbiol. 2016, 7, 899. [CrossRef] [PubMed]

24. Ceylan, O.; Okmen, G.; Ugur, A. Isolation of soil Streptomyces as source of antibiotics active against antibiotic-resistant bacteria. EurAsian J. Biosci. 2008, 2, 73-82.

25. Junaid, S.; Dileep, N.; Rakesh, K.N.; Kekuda, P.T.R. Antimicrobial and antioxidant efficacy of Streptomyces species SRDP-TK-07 isolated from a soil of Talakaveri, Karnataka, India. Pharmanest 2013, 4, 736-750.

26. Bennur, T.; Kumar, A.R.; Zinjarde, S.; Javdekar, V. Nocardiopsis species as potential sources of diverse and novel extracellular enzymes. Appl Microbiol Biotechnol. 2014, 98, 9173-9185. [CrossRef]

27. Fiedler, H.P.; Bruntner, C.; Bull, A.T. Marine actinomycetes as a source of novel secondary metabolites. Ant. V. Leeuw. 2004, 87, 37-42. [CrossRef]

28. Sengupta, S.; Pramanik, A.; Ghosh, A.; Bhattacharyya, M. Antimicrobial activities of actinomycetes isolated from unexplored regions of Sundarbans mangrove ecosystem. BMC Microbiol. 2015, 15, 170. [CrossRef]

29. Satheeja, S.; Jebakumar, S.R.D. Phylogenetic analysis and antimicrobial activities of Streptomyces isolates from mangrove sediment. J. Basic Microbiol. 2011, 51, 71-79. [CrossRef]

30. Vu, H.T.; Nguyen, D.T.; Nguyen, H.Q. Antimicrobial and cytotoxic properties of bioactive metabolites produced by Streptomyces cavourensis YBQ59 isolated from Cinnamomum cassia Prels in Yen Bai province of Vietnam. Curr. Microbiol. 2018, 75, 1247-1255. [CrossRef]

31. Dashti, Y.; Grkovic, T.; Abdelmohsen, U.R. Production of induced secondary metabolites by a co-culture of sponge-associated actinomycetes, Actinokineospora sp. EG49 and Nocardiopsis sp. RV163. Mar. Drugs 2014, 12, 3046-3059. [CrossRef] [PubMed]

32. Rodríguez, V.; Martín, J.; Sarmiento-Vizcaíno, A. Anthracimycin B, a potent Antibiotic against gram-positive bacteria isolated from cultures of the deep-sea actinomycetes Streptomyces cyaneofuscatus M-169. Mar. Drugs 2018, 16, 406. [CrossRef] [PubMed] 
33. Shobha, K.S.; Onkarappa, R. In vitro susceptibility of C. albicans and C. neoformens to potential metabolites from Streptomycetes. Indian J. Microbiol. 2011, 51, 445-449. [CrossRef] [PubMed]

34. Manasa, M.; Poornima, G.; Abhipsa, V.; Rekha, C.; Prashith, K.T.R.; Onkarappa, R.; Mukunda, S. Antimicrobial and antioxidant potential of Streptomyces sp. RAMPP-065 isolated from Kudremukh soil, Karnataka, India. Sci. Technol. Arts Res. J. 2012, 1, 39-44. [CrossRef]

35. Gautham, S.A.; Onkarappa, R. Pharmacological activities of metabolite from Streptomyces fradiae strain GOS1. Int. J. Chem. 2013, 11, 583-590.

36. Chang, H.B.; Kim, J.-H. Antioxidant properties of dihydroherbimycin A from a newly isolated Streptomyces sp. Biotechnol. Lett. 2007, 29, 599-603. [CrossRef]

37. Saurav, K.; Kannabiran, K. Cytotoxicity and antioxidant activity of 5-(2, 4-dimethylbenzyl) pyrrolidin-2-one extracted from marine Streptomyces VITSVK5 spp. Saudi J. Biol. Sci. 2012, 19, 81-86. [CrossRef]

38. Ser, H.L.; Palanisamy, U.D.; Yin, W.F.; Malek, S.N.A.; Chan, K.G.; Goh, B.H. Presence of antioxidative agent, Pyrrolo[1,2-a] pyrazine-1,4-dione, hexahydro-in newly isolated Streptomyces mangrovisoli sp. nov. Front. Microbiol. 2015, 6, 854. [CrossRef]

39. Narendhran, S.; Rajiv, P.; Vanathi, P.; Sivaraj, R. Spectroscopic analysis of bioactive compounds from Streptomyces cavouresis kuv39: Evaluation of antioxidant and cytotoxicity activity. Int. J. Pharm. Pharm. Sci. 2014, 6, 319-322.

40. Tian, S.Z.; Pu, X.; Luo, G.; Zhao, L.X.; Xu, L.H.; Li, W.J.; Luo, Y. Isolation and characterization of new p-Terphenyls with antifungal, antibacterial, and antioxidant activities from halophilic actinomycete Nocardiopsis gilva YIM 90087. J. Agric. Food Chem. 2013, 61, 3006-3012. [CrossRef]

(C) 2020 by the authors. Licensee MDPI, Basel, Switzerland. This article is an open access article distributed under the terms and conditions of the Creative Commons Attribution (CC BY) license (http://creativecommons.org/licenses/by/4.0/). 